Article

\title{
Partial Discharge in Nanofluid Insulation Material with Conductive and Semiconductive Nanoparticles
}

\author{
Mohamad Zul Hilmey Makmud ${ }^{1,2, * \mathbb{C}}$, Hazlee Azil Illias ${ }^{1, *} \mathbb{\infty}$, Ching Yern $\mathrm{Chee}^{3}$ and \\ Sameh Ziad Ahmad Dabbak ${ }^{1}$ \\ 1 UM High Voltage Laboratory (UMHVL), Department of Electrical Engineering, Faculty of Engineering, \\ University of Malaya, Kuala Lumpur 50603, Malaysia; al_dabak@hotmail.com \\ 2 Complex of Science and Technology, Faculty of Science and Natural Resources, Universiti Malaysia Sabah, \\ Kota Kinabalu 88400, Malaysia \\ 3 Department of Chemical Engineering, Faculty of Engineering, University of Malaya, Kuala Lumpur 50603, \\ Malaysia; chingyc@um.edu.my \\ * Correspondence: mzhilmey@ums.edu.my (M.Z.H.M.); h.illias@um.edu.my (H.A.I.); \\ Tel.: +603-79674483 (H.A.I.)
}

Received: 24 January 2019; Accepted: 13 February 2019; Published: 11 March 2019

\begin{abstract}
This study provides a thorough investigation of partial discharge (PD) activities in nanofluid insulation material consisting of different types of nanoparticles, which are conductive and semiconductive when subjected to high voltage stress is presented. Nanofluids have become a topic of interest because they can be an alternative to liquid insulation in electrical apparatus due to their promising dielectric strength and cooling ability. However, during in-service operation, PDs can occur between conductors in the insulation system. Therefore, this study presents the behavior of PDs within nanofluid dielectric materials consisting of conductive and semiconductive nanoparticles. The results show that there is an improvement in the PD resistance and a reduction in the tan delta of nanofluids at power frequency after the incorporation of conductive or semiconductive nanoparticles in the nanofluid oil. However, the most suitable concentration of conductive and semiconductive nanoparticles in the base fluid was found to be, respectively, $0.01 \mathrm{~g} / \mathrm{L}$ and $1.0 \mathrm{~g} / \mathrm{L}$ at PD inception and PD steady-state conditions. The clustering of nanoparticles in a nanofluid suspension due to PD activities is also discussed in this study.
\end{abstract}

Keywords: nanofluid; partial discharge; high voltage; electrical insulation

\section{Introduction}

A high voltage transformer is a key component in an electrical power system network. It plays a vital role in each division of power system grid, which are generation, transmission, and distribution. The majority of high voltage transformers depends on liquid dielectric as an insulation material. In recent years, advances in nanotechnology have led to the formation of a remarkable new material, nanofluid insulation, which is produced through the addition of nanoparticles to a base insulating liquid. Insulation-based-nanofluid has been shown to have high dielectric strength and significant improvement in cooling ability compared to the base materials [1,2]. However, the majority of these nanofluid insulations are not yet commercially available due to certain problematic factors that require further investigation [3] — for instance, the stability of nanoparticles when being dispersed into a base fluid, interaction with the magnetic field in a transformer, and the effect of high electric field on the performance of nanofluids over time.

Therefore, one of the significant factors to be considered is the influence of the electrical properties of nanoparticles on partial discharge (PD) behavior in nanofluids. Generally, PD can occur inside 
a liquid insulation system when the electric field is enhanced in a localized area between the dielectric material and the conductor. This leads to the acceleration of thermal aging and streamer breakdown development [4]. Herchl et al. carried out PD measurements in a magnetic-based nanofluid insulation [5]. They found that PDs contributed to losses and caused a progressive degradation of the nanofluid. In nanodielectrics, it is commonly accepted that adding inorganic nanoparticles into a polymer matrix is an effective method to enhance PD resistance of solid insulation [6,7]. Nanoparticles act as a systemic barrier to prevent the insulation from high-energy bombardment activities, such as PDs [8]. Moreover, in the nanofluid, the species on the nanoparticle's surface affected the discharge dynamics. As reported in $[9,10]$, silica nanoparticles can adsorb water, acid, or impurities, leading to a reduction in PD activities, as well as improve the breakdown voltage of the insulation oil.

Recent research has postulated that the enhancement of dielectric strength of nanofluid is due to electron trapping on the surface of the nanoparticles [11-13]. It has been suggested that the trapping mechanisms of nanoparticles are dependent on charge induction in conductive nanoparticles or by polarization in semiconductive and insulating nanoparticles. However, there are no comparative studies on the influence of the electrical properties of different nanoparticles, such as conductivity and permittivity, on PD behaviour in nanofluid insulation material. Therefore, this study provides an opportunity to gain a better understanding on the matter by comparing PD behaviour in nanofluids, which consist of conductive and semi-conductive nanoparticles dispersed in natural ester oil.

In this study, at the beginning, tan delta measurements were obtained in order to assess the initial performance of the base oil after the incorporation of different types of nanoparticles. Then, the influence of the electrical properties of these nanoparticles on PD activities was studied under two conditions: inception and steady-state conditions. PDs data at the inception condition were used to calculate the probability of PD occurrences using Weibull distribution. The results from steady-state condition were statistically compared in term of PD characteristics, which include PD events, total PD charges, maximum charge magnitude, and PD patterns.

\section{Materials and Methods}

\subsection{Sample Preparation}

Highly-refined palm oil (PO) was used as natural ester-based insulating fluid (NE) [14]. Two different types of nanoparticles-Iron (III) oxide $\left(\mathrm{Fe}_{3} \mathrm{O}_{4}\right) \geq 97 \%$ and Titanium dioxide $\left(\mathrm{TiO}_{2}\right) \geq$ 99.5\% -were applied to prepare the samples of natural ester with conductive nanoparticles (CNF) and natural ester with semiconductive nanoparticles (SNF), respectively. The base fluid and nanoparticles, which were commercially obtained, were kept for $24 \mathrm{~h}$ at the elevated temperature $\left(80^{\circ} \mathrm{C}\right.$ for the base fluid and $300{ }^{\circ} \mathrm{C}$ for nanoparticles) and under vacuum conditions ( $90 \mathrm{kPa}$ ) to remove moisture and impurities. The average of water content for the base fluid was recorded as $110.63 \mathrm{ppm}$ using Metrohm Karl Fischer (KF) Coulometer.

Six samples of natural ester-based nanofluids were prepared by ultrasonication for $30 \mathrm{~min}$ at room temperature using an ultrasonic bath (output power $=120 \mathrm{~W}$, frequency $=40 \mathrm{kHz}$ ). The abbreviation for each sample is shown in Table 1 . The aggregate distribution size of the nanofluids is measured at $\leq$ $100 \mathrm{~nm}$ using dynamic light scattering (DLS) with a Malvern Zetasizer (Malvern, UK). All samples are visually stable after $24 \mathrm{~h}$ as reported in the previous study [15]. 
Table 1. Weight fraction of nanofluid formulation samples.

\begin{tabular}{ccc}
\hline \multirow{2}{*}{ Sample Abbreviation } & \multicolumn{2}{c}{ Amount of Nanoparticles [g/L] } \\
\cline { 2 - 3 } & $\mathrm{Fe}_{3} \mathrm{O}_{4}$ & $\mathrm{TiO}_{2}$ \\
\hline $\mathrm{NE}$ & - & - \\
$\mathrm{CNF} 1$ & 0.01 & - \\
$\mathrm{CNF2}$ & 0.1 & - \\
$\mathrm{CNF3}$ & 1.0 & - \\
$\mathrm{SNF1}$ & - & 0.01 \\
$\mathrm{SNF2}$ & - & 0.1 \\
$\mathrm{SNF3}$ & - & 1.0 \\
\hline
\end{tabular}

\subsection{Tan Delta Measurement Method}

Tan delta was measured to evaluate the nanofluid insulation quality with the existence of nanoparticles by the ratio between dielectric loss $\varepsilon^{\prime \prime}$ and dielectric constant $\varepsilon^{\prime}$. Electrochemical Impedance Spectroscopy (EIS) method was used by applying a $1 \mathrm{~V}$ peak-to-peak voltage at the frequency range between $0.1 \mathrm{~Hz}$ and $0.1 \mathrm{MHz}$ at room temperature conditions. The setup consisted of two cylindrical copper plates (working and ground electrodes) with a diameter of $25 \mathrm{~mm}$ and $100 \mu \mathrm{m}$ gap distance. Both electrodes were fully immersed in the fluid under test. Tan delta was measured before each sample was stressed with the applied voltage for PD measurement. The tan delta was obtained from the dielectric loss and dielectric constant values by applying

$$
\tan \delta=\frac{\varepsilon^{\prime \prime}}{\varepsilon^{\prime}}
$$

\subsection{PD Measurement Method}

The Mtronix MPD 600 setup manufactured by Omicron (Germany) was used for PD measurement in conjunction with a high voltage generation kit. The schematic diagram of the PD measurement system is shown in Figure 1. The transformer has a rating of $0.22 / 100 \mathrm{kV}, 100 \mathrm{kVA}$. The PD signals measured by the MPD 600 were in current pulses across the nanofluid sample between the needle and plane electrodes. When PDs occur, the coupling capacitor transfers equivalent charges to the test object to preserve the voltage drop across the electrodes. Voltage pulses in the nanosecond range are detected by the coupling device and the PD detector, which are transferred through fibre optics to a personal computer $(\mathrm{PC})$.

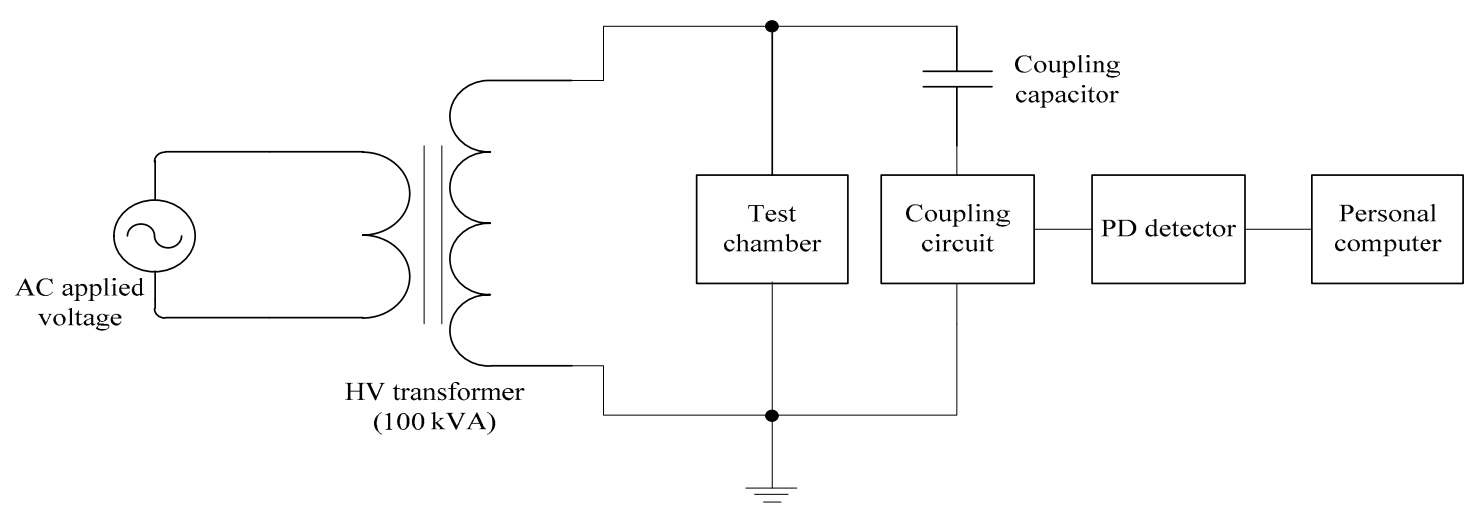

Figure 1. Partial discharge (PD) measurement setup.

Figure 2 shows a schematic diagram of the test chamber used for PD measurement in a nanofluid sample. The self-fabricated chamber was adopted from IEC 60343 configuration which consists of two conductors; high voltage and ground stainless steel electrodes. The rod electrode has a $1 \mathrm{~mm}$ curvature radius and $10 \mathrm{~mm}$ gap distance to the plane electrode. The edges of the test chambers were 
sealed with silicone glue to prevent the fluid under test from spilling out. This setup allows PDs to occur without causing any breakdown. The nanofluid samples of $400 \mathrm{~mL}$ volume in test chamber were stressed by being subjected to $50 \mathrm{~Hz}$ sinusoidal applied voltage. The voltage was controlled at a rate of rise of $1 \mathrm{kV} / \mathrm{s}$. The PD measurement consists of two conditions:

- Inception condition: Measurement was taken immediately after the first PD occurrence. The applied voltage $U_{\text {app }}$ was ramped-up from 0 to $25 \mathrm{kV}$.

- Steady-state condition: Measurement was taken after $30 \mathrm{~min}$ of the applied voltage. The applied voltage $U_{a p p}$ was fixed at 26,28 , and $30 \mathrm{kV}$.

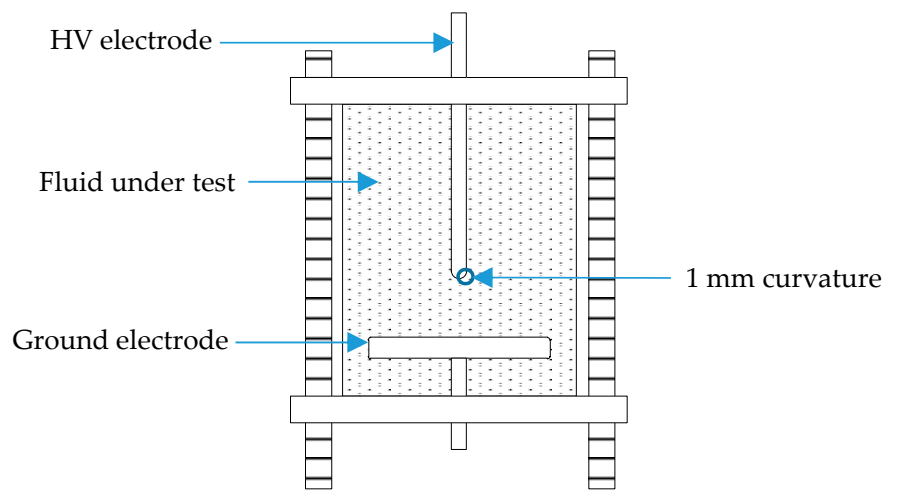

Figure 2. Schematic diagram of the test chamber for PD measurement.

\section{Results}

\subsection{Tan Delta Before PD Activities}

The results of tan delta measurement as a function of frequency and nanoparticle concentration are shown in Figure 3. At lower frequencies $(0.1 / 1.0 / 10 \mathrm{~Hz})$, higher variation in the tan delta measurements can be clearly seen. This is possibly due to Maxwell-Wagner-Sillars (MWS) interfacial polarization, where the frequency-dependent contributes to the formation of the charge build-up at the nanoparticle interfaces and dipole molecules of the base oil [16]. At higher frequencies $(1 \mathrm{k} / 10 \mathrm{k} / 0.1 \mathrm{M} \mathrm{Hz})$, it can be seen that the tan delta is strongly influenced by the increment of the frequencies, where the tan delta drops below 0.02 for all samples.

While investigating the influence of nanoparticles in the base oil at power frequency $(50 / 60 \mathrm{~Hz})$, it is noteworthy that the tan delta peak decreases with the addition of conductive and semiconductive nanoparticles, except for $\mathrm{Fe}_{3} \mathrm{O}_{4}$ at $1.0 \mathrm{~g} / \mathrm{L}$. The reduction in tan delta values is associated with the restriction on the mobility imposed by the interaction between nanoparticle electron trapping capabilities and the base oil molecules [17]. When considering the effect of nanoparticle concentration, the tan delta response of the natural ester with conductive nanoparticles (CNF) appears to differ from that associated with the natural ester with semiconductive nanoparticles (SNF). For CNFs, the increasing concentrations up to $1.0 \mathrm{~g} / \mathrm{L}$ results in a tube-tube conduction mechanism between the particles. This condition is associated with high surface conductivity of $\mathrm{Fe}_{3} \mathrm{O}_{4}$ and particle concentration. As the volume fraction is increased as shown in Figure 3a, tan delta becomes higher due to the increasing interfacial charge conductivity as obtained experimentally.

More importantly, the presence of high amount of conductive nanoparticles in a base fluid means a greater likelihood of tube-tube conduction than in the case of low conductive particles, which refers to $\mathrm{TiO}_{2}$ in this instance. With the presence of $\mathrm{TiO}_{2}$, there is a slight decrement of tan delta towards the increment of $\mathrm{TiO}_{2}$ concentration, such that it still remains less than the base oil, as shown in Figure 3b. This could be due to the reflection of low interfacial charge conductivity upon the increment of $\mathrm{TiO}_{2}$ concentration, which subsequently affects the tan delta value. When the content of nanoparticles is increased, it is more difficult to achieve good dispersion of nanoparticles throughout the suspension 
and aggregation can occur. This results in different interphase conductivity regions, which causes the increment or decrement of tan delta values with increasing nanoparticle concentration.

It is noteworthy that the addition of $\mathrm{Fe}_{3} \mathrm{O}_{4}$ or $\mathrm{TiO}_{2}$ in a certain amount $(0.01 / 0.1 / 1.0 \mathrm{~g} / \mathrm{L})$ to base oil occasionally resulted in a small difference in the tan delta response of nanofluids, as can be seen in CNF1-CNF2 and SNF2-SNF3. Although this effect could be associated with the introduction of nanoparticles itself as described previously, as with such cases, it may be suggested that the observed responses are due to the presence of the polar species [18]. With an increasing or decreasing number of nanoparticles, more or less surface hydroxyl groups will present at the interfaces, resulting in a direct consequence on the tan delta values.

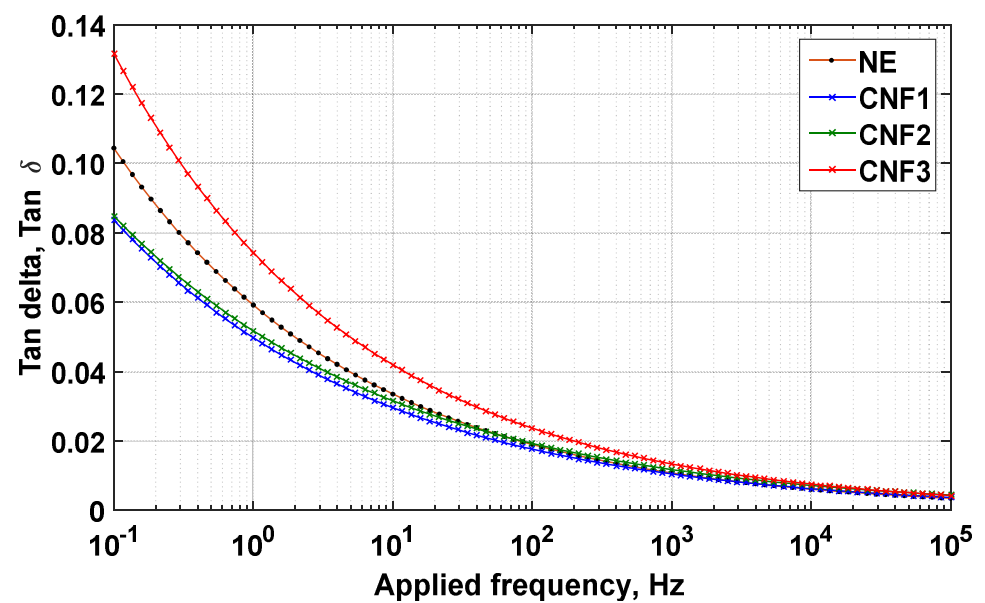

(a)

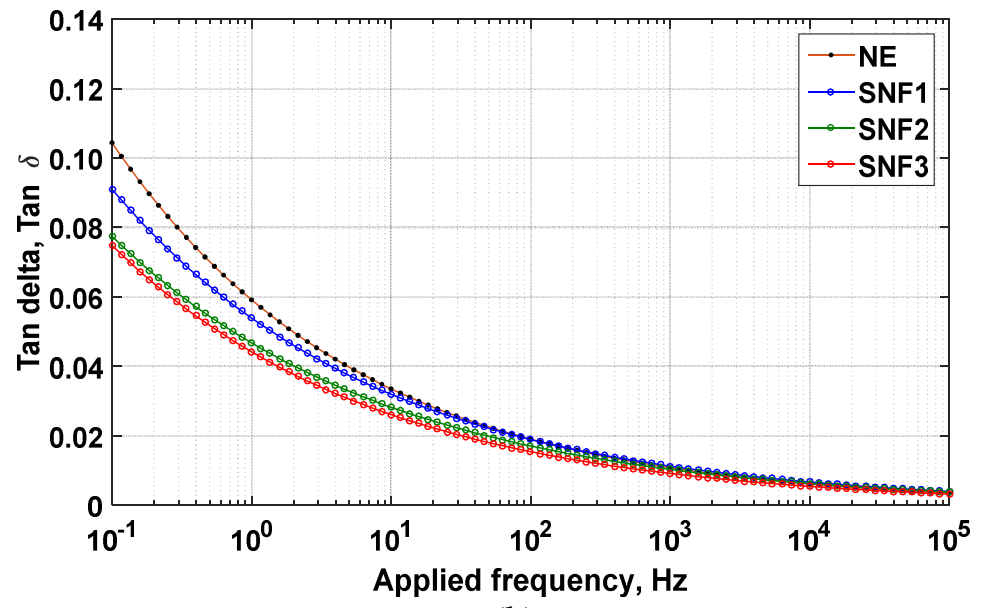

(b)

Figure 3. Tan delta as a function of applied frequency for (a) CNF and (b) SNF samples.

\subsection{PD Activities at Inception Stage}

Partial discharge inception voltage (PDIV) was recorded at the inception condition of the PD measurement when the applied voltage magnitude was increased until the first $100 \mathrm{pC}$ of PD occurred, based on IEC 61294. An occurrence probability distribution of PDIV average results according to Weibull statistical function, which was plotted for each of sample, is shown in Figure 4 . Since the lowest inception voltage at which PD occurs is also the main interest for insulation applications, it is important to observe the lower tail of the Weibull distribution slope. Table 2 shows the Weibull parameters for each sample, where $\alpha$ or the scale parameter is the PDIV at $60 \%$ of cumulative probability, $\beta$ is the shape parameter, which indicates the range of PDIV values within the distribution, and $U_{1 \%}$ is the prediction of PDIV at $1 \%$ of probability. 


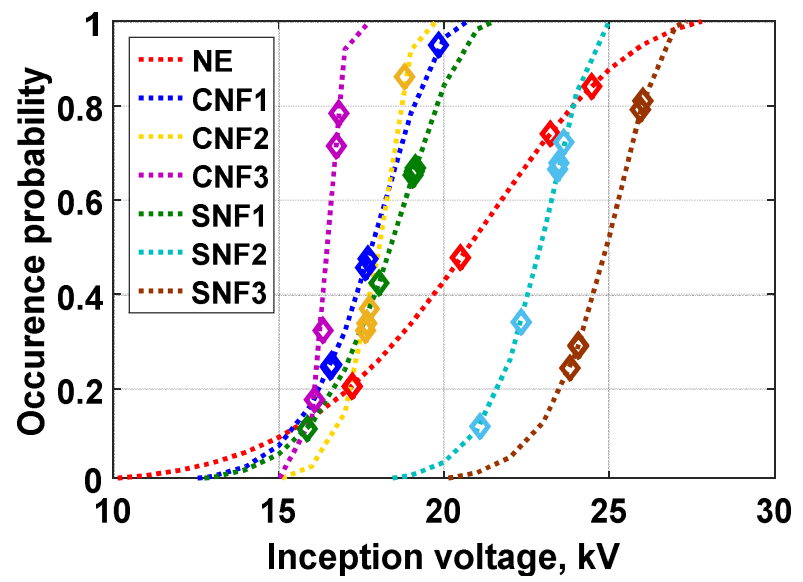

Figure 4. Weibull distribution of PDIV average values for base oil and nanofluid samples.

Table 2. Weibull parameters of the average partial discharge inception voltages.

\begin{tabular}{cccc}
\hline Samples & Shape Parameter, $\boldsymbol{\beta}$ & $\begin{array}{c}\text { PDIV Average Value at } \\
\mathbf{6 0} \mathbf{\%}, \boldsymbol{\alpha} \mathbf{( k V )}\end{array}$ & $\begin{array}{c}\text { PDIV Withstand Value, } \\
\boldsymbol{U}_{\mathbf{1} \%} \mathbf{( k V )}\end{array}$ \\
\hline NE & 5.95 & 22.05 & 10.18 \\
CNF1 & 12.40 & 18.35 & 12.66 \\
CNF2 & 21.49 & 18.30 & 15.20 \\
CNF3 & 47.14 & 16.67 & 15.12 \\
SNF1 & 11.77 & 18.97 & 12.83 \\
SNF2 & 20.15 & 23.34 & 18.58 \\
SNF3 & 20.21 & 25.37 & 20.21 \\
\hline
\end{tabular}

In general, the shape parameter $\beta$ of all nanofluid samples is higher than the base oil. This indicates that the incorporation of nanoparticles leads to the narrower distribution of PDIV, or in other words, the localization of PD. A very high localization of PD occurrences is exhibited by the sample with the highest conductive nanoparticle concentration, namely CNF3. The cumulative probability $\alpha$ shows that the incremental increase in nanoparticle concentration contributes to a reduction in PDIV for CNF samples, but there is a significant escalation for SNF nanofluids. At the lowest probability of the inception condition $U_{1 \%}$, all nanofluid samples, especially SNF3, have a higher PD tolerance compared to the base oil. This is due to the trapping characteristics of nanoparticles on the charge mobility for both types of nanofluids. Similar observations were also reported by Cavallini et al. in [19].

\subsection{PD Activities at Steady State Condition}

\subsubsection{Effect of Nanoparticles Type}

The PD measurement results for NE, CNF1, and SNF1 at a steady state of $26 \mathrm{kVrms}$ of applied voltage are shown in Figure 5. With the addition of $\mathrm{Fe}_{3} \mathrm{O}_{4}$ and $\mathrm{TiO}_{2}$ nanoparticles, the number of PD events, total charge, mean charge, and maximum charge magnitude are lower compared to the base oil. A comparison between conductive and semiconductive-based nanofluids with equal nanoparticle concentration $(0.01 \mathrm{~g} / \mathrm{L})$, clearly indicates that the addition of small amounts of conductive nanoparticles, such as $\mathrm{Fe}_{3} \mathrm{O}_{4}$, enhances the PD resistance of nanofluids more effectively than the semiconductive-based $\mathrm{TiO}_{2}$.

To explain the differences between the two types of nanoparticles, according to Sima et al., under the applied electric field, both are induced and polarized within a very short timescale [13]. The electrons initiated by charge injection move quickly towards the positively-charged nanoparticle surface. This process represents the electron catchment on the nanoparticle surface and reduces the electron movement and PD activities. Upon completion of the charge catchment, spherical nanoparticles are saturated with negative charges, and thereby no longer trap the electron. The value of charge saturation for each 
type of nanoparticle is determined by the value of their conductivity and permittivity, where $\mathrm{Fe}_{3} \mathrm{O}_{4}$ nanoparticles can potentially trap higher number of electrons compared to $\mathrm{TiO}_{2}$.

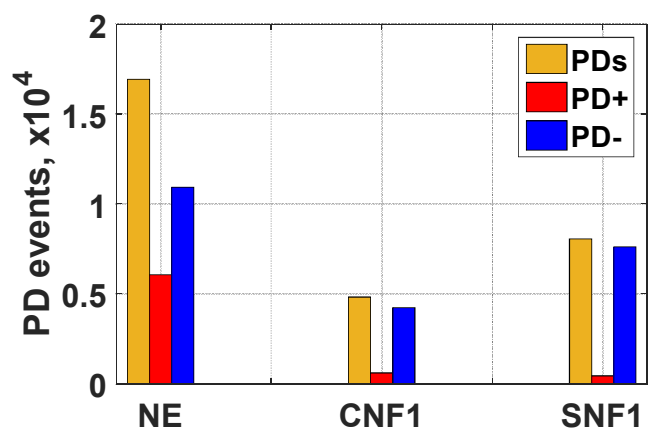

(a)

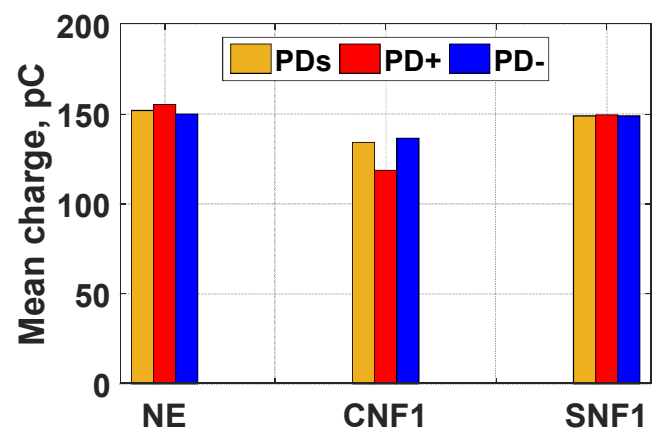

(c)

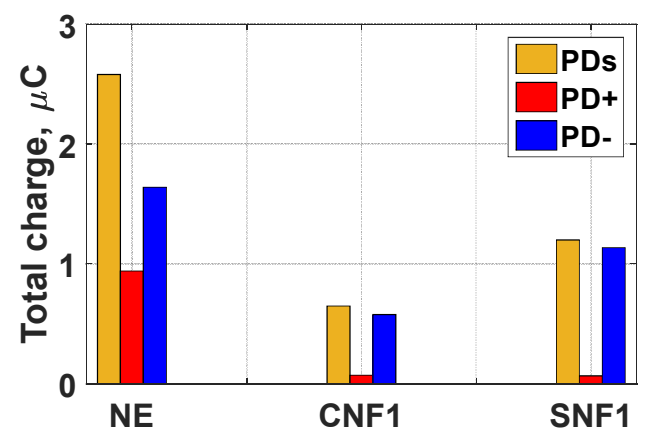

(b)

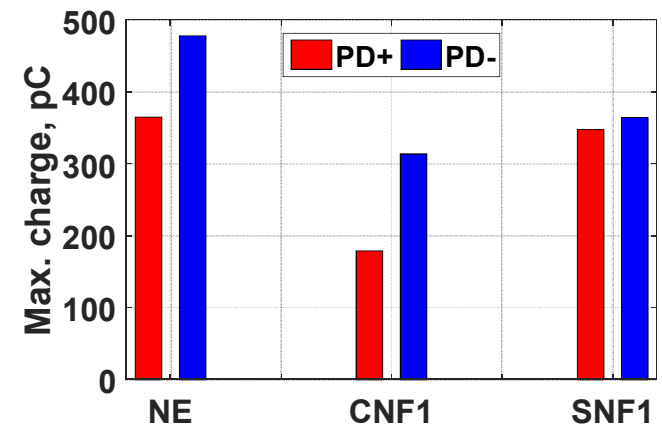

(d)

Figure 5. PD measurement results at $26 \mathrm{kVrms}$ in 1500 cycles; (a) PD events, (b) total charge, (c) mean charge, and (d) maximum charge magnitude.

Figure 6 presents the PD phase distributions of NE, CNF1, and SNF1 nanofluids. The PD phase distribution shows that most PDs occur from $45^{\circ}$ to $113^{\circ}$ and $180^{\circ}$ to $270^{\circ}$. The peak of the distribution is slightly higher at $180^{\circ}$ to $270^{\circ}$ for each sample. This is due to the influence of the larger area of the ground electrode in the ionization process during the charge injection. The molecular ionization, which causes the PD occurrences, is dependent on the electric field and geometry of the electrodes. In this mechanism, a high electric field derives a free electron from a neutral molecule and generates a positive ion. The electrons with high mobility relative to positive ions are swept away from the ionization zone and are absorbed by the positive electrode and initiate PDs [11]. In the case of nanofluids, the charging of nanoparticles takes place, during which many of the mobile free electrons produced by the ionization are trapped before they can reach the electrode.

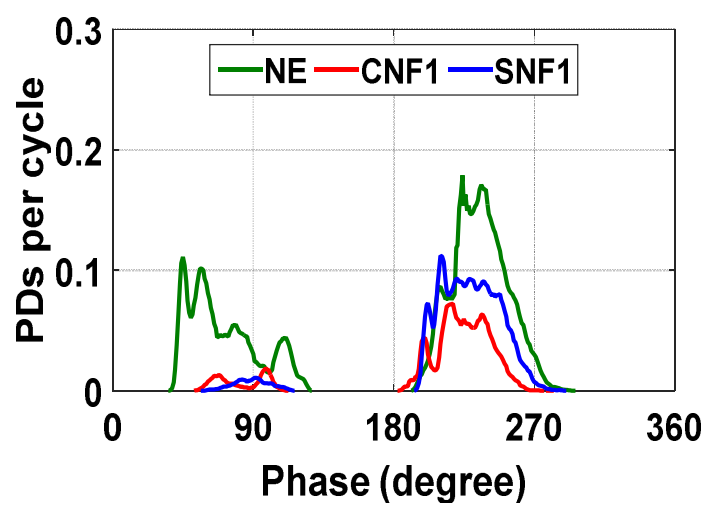

Figure 6. PD phase distribution as a function of nanoparticle type. 


\subsubsection{Effect of Applied Voltage}

The PD results obtained for NE, CNF1, and SNF1 as a function of $50 \mathrm{~Hz}$ applied voltage amplitude is shown in Figure 7. With increased voltage, the PD events, total charge, mean charge, and maximum charge magnitude also increase, but the mean charge for CNF1 is almost constant. When the applied voltage is increased, the electric field is also increased and the ionization process is enhanced, increasing the free electron generation rate. At this stage, PD events are boosted almost linearly with the applied voltage. The total charge also increases with additional applied voltage due to higher PD occurrences [20]. The mean charge magnitude increases as the applied voltage is increased. Furthermore, the maximum charge magnitude increases with additional applied voltage because higher applied voltage magnitude provides a larger voltage drop across the electrodes when a PD occurs. In the case of nanofluids, both show a lower number of PD activities compared to the base oil at different applied voltage amplitudes.

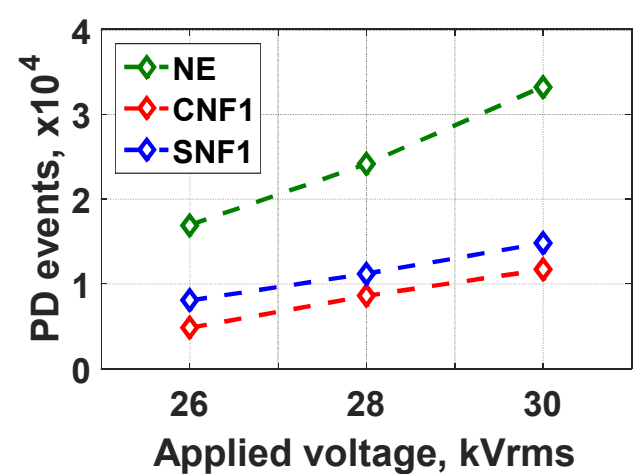

(a)

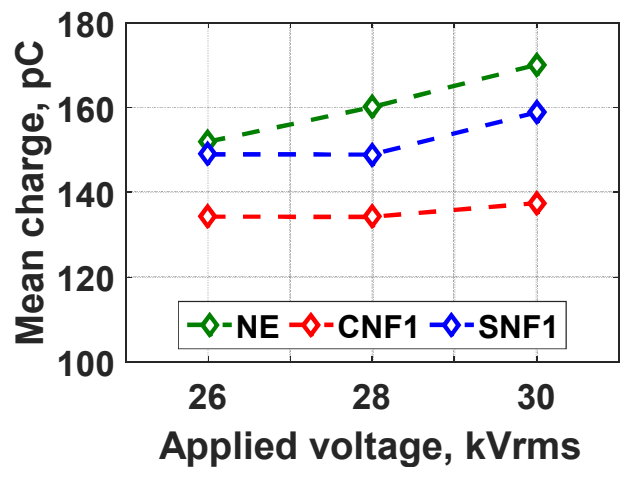

(c)

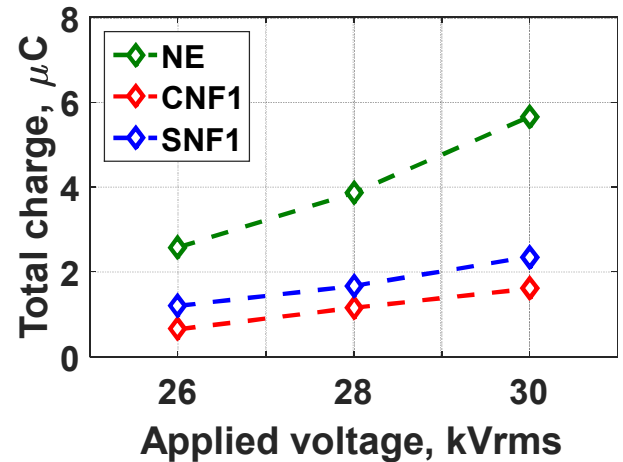

(b)

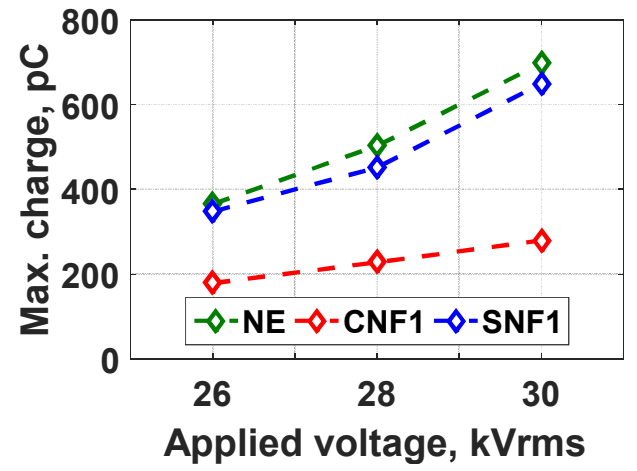

(d)

Figure 7. PD activities as a function of the applied voltage amplitudes in 1500 cycles; (a) PD events, (b) total charge, (c) mean charge, and (d) maximum charge magnitude.

\subsubsection{Effect of Particles Weight Fraction}

The phase-resolved partial discharge (PRPD) patterns obtained from the experiments are presented in Figure 8. It can be seen that PDs usually occur between $45^{\circ}$ and $100^{\circ}$ in the positive cycle and between $180^{\circ}$ and $270^{\circ}$ in the negative cycle. Since the electron generation rate is enhanced by the larger surface area of the ground electrode, this causes more PDs to occur during the negative cycle. Referring to CNF samples, the intensity and magnitude of PDs increase significantly with increasing concentrations of conductive nanoparticles (CNF1, CNF2, and CNF3 samples). Previous research reported that the magnitude and repetition rates of $\mathrm{PDs}$ are slightly higher for $\mathrm{Fe}_{3} \mathrm{O}_{4}$ compared to semiconductive and insulating nanoparticle types [19]. Increasing $\mathrm{Fe}_{3} \mathrm{O}_{4}$ concentration up to a certain ratio will also increase the electric dipole-dipole interaction between particles and support their agglomeration and conduction. This consequently leads to the electric field increment between the electrodes, increasing the PD numbers and magnitude. 
For SNF samples, the number of PDs and their magnitude decrease with the increasing concentration of semiconductive nanoparticles (SNF1, SNF2, and SNF3). Under certain conditions, such as $1.0 \mathrm{~g} / \mathrm{L}$ of $\mathrm{TiO}_{2}$ concentration, no clear PD activities was obtained from the measurement in the positive cycle. This could be due to the increase in resistance against $\mathrm{PDs}$ when $\mathrm{TiO}_{2}$ nanoparticles were added to the suspension. Increasing $\mathrm{TiO}_{2}$ concentration will also increase dipole-dipole interaction between particles and support the agglomeration process. However, due to the low conductivity of the $\mathrm{TiO}_{2}$ nanoparticle surface, it leads to insulation mechanism rather than conduction and trapping of the charge with increasing electron trap density [21]. In contrast, the reduction of PD activities due to the existence of nanoparticles could be beneficial to the power transformer design, where it can reduce its size and space for liquid insulation.

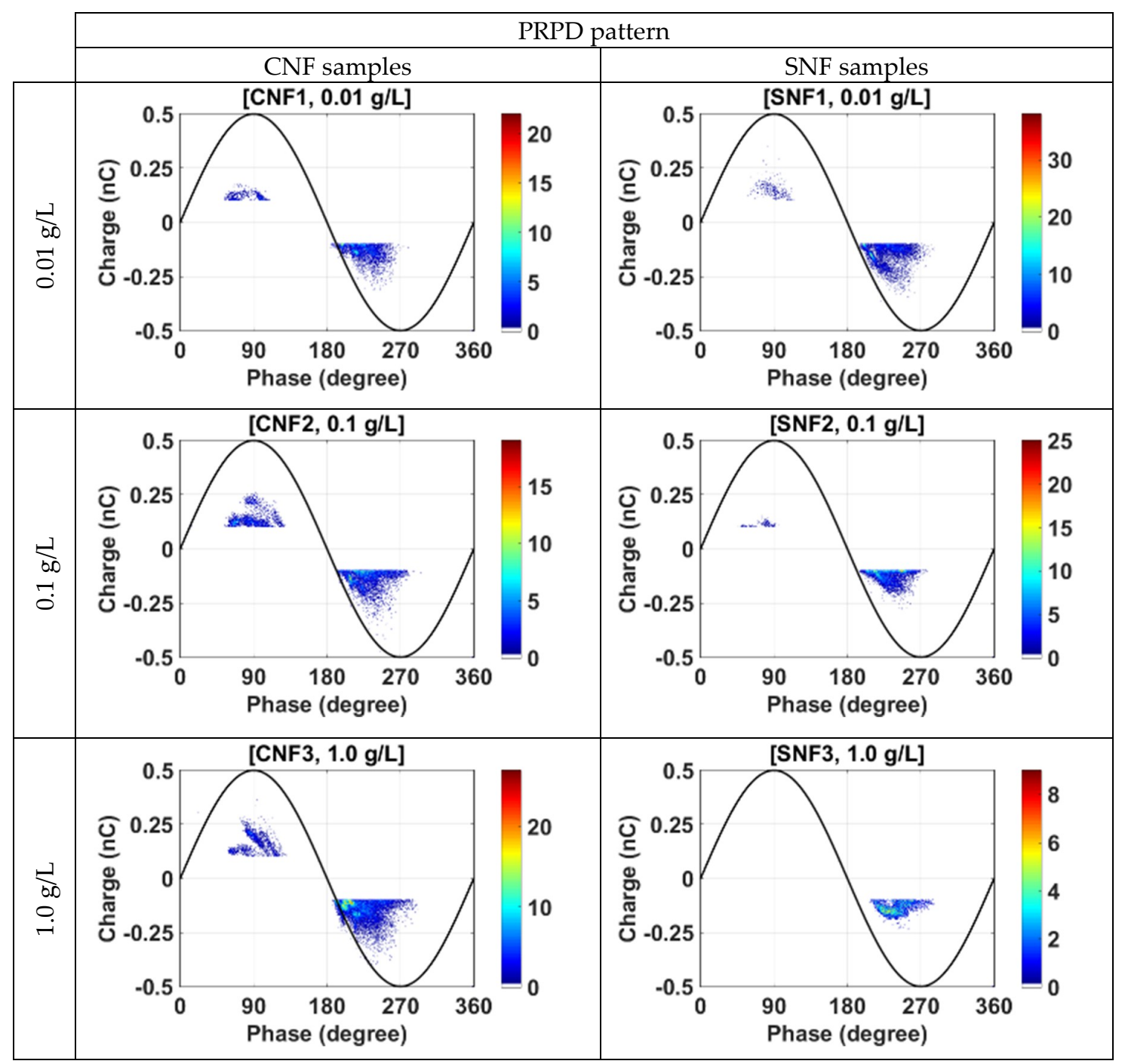

Figure 8. PRPD patterns for nanofluid samples with conductive and semiconductive nanoparticles at $26 \mathrm{kVrms}$ applied voltage in 1500 cycles.

\section{Discussion}

Under applied high voltage magnitude, the electric field is the main contribution to the ionization process, which leads to PD occurrences and breakdown when the insulation material exceeds the tolerance limit. However, the addition of nanoparticles into the base material modifies the electric field distribution between the electrodes, thus enhancing the insulation performance. 
In order to understand the enhancement mechanism in this study, a Finite Element Analysis (FEA) model was developed. The simulated electric equipotential lines and the electric field distribution from the FEA model, with and without nanoparticle $\left(\mathrm{Fe}_{3} \mathrm{O}_{4}\right.$ and $\left.\mathrm{TiO}_{2}\right)$, are shown in Figure 9. The model consists of a spherical nanoparticle of $50 \mathrm{~nm}$ diameter suspended in a natural ester oil, which is immersed between two-plane electrode gap of $100 \mathrm{~nm}$ under $50 \mathrm{~Hz}, 10 \mathrm{kV}$ AC applied voltage. The conductivity values of $\mathrm{Fe}_{3} \mathrm{O}_{4}$ and $\mathrm{TiO}_{2}$ were set as $1 \times 10^{5}$ and $1 \times 10^{-11} \mathrm{~S} / \mathrm{m}$, respectively, while the permittivity values were set as 80 and 100 according to the literature [22]. The results are similar with the previous simulation results obtained from a model of a spherical nanoparticle suspended in transformer oil with various permittivity values [23]. Other published research has also used FEA software to obtain the distribution of electric field within nanofluid during streamer discharges [24,25].

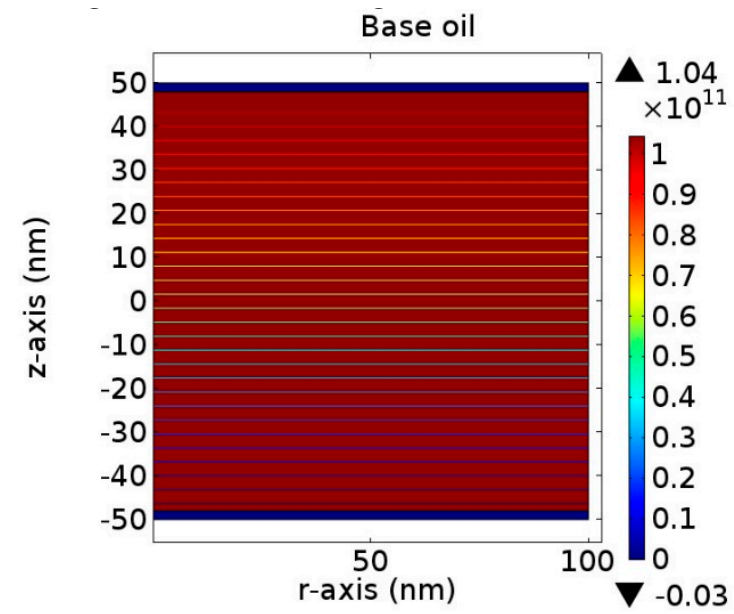

(a)

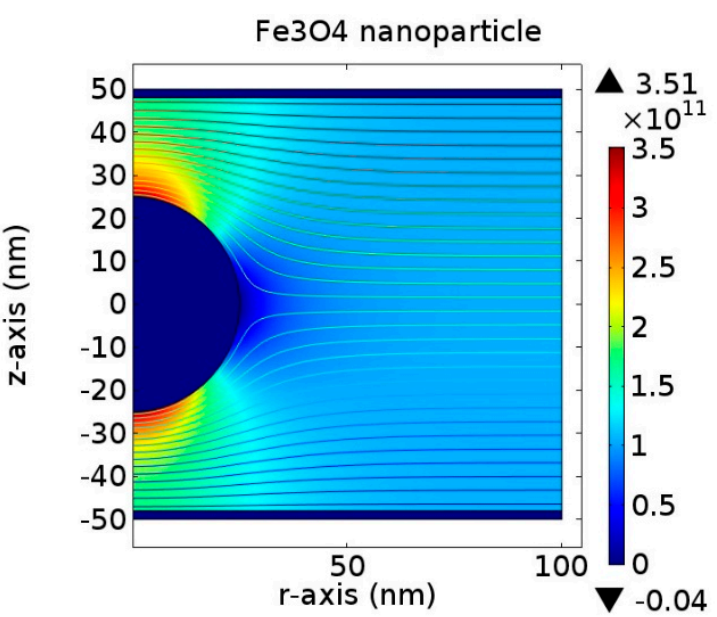

(b)

TiO2 nanoparticle

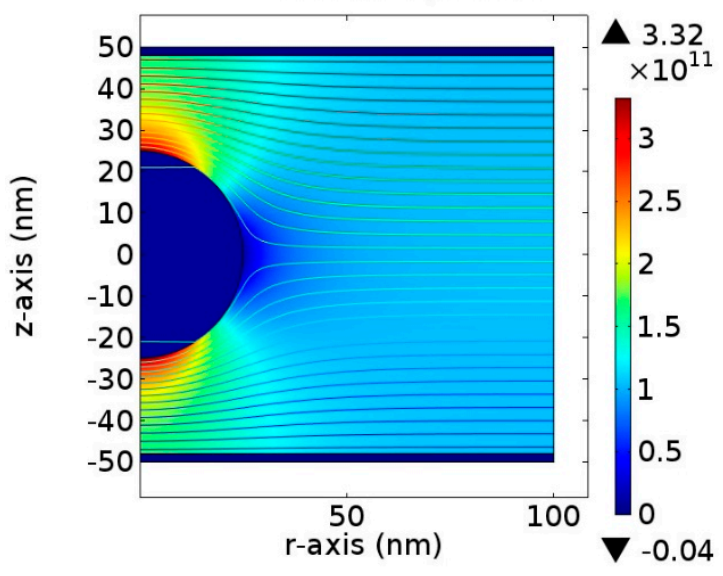

(c)

Figure 9. Electric field $(\mathrm{V} / \mathrm{m})$ distribution and electric equipotential lines for (a) base oil, (b) with $\mathrm{Fe}_{3} \mathrm{O}_{4}$ and (c) $\mathrm{TiO}_{2}$ nanoparticle.

In Figure 9a, the electric field of the base oil and surrounding area between the electrodes system is uniformly distributed, since the electrical properties of the dielectric are homogenously constant. The maximum value of the electric field is $1.04 \times 10^{11} \mathrm{~V} / \mathrm{m}$. When a nanoparticle was added in the oil, the electric field is significantly altered, as shown in Figure 9b,c. Due to the charging dynamic effect, suspending a nanoparticle into base oil results in a higher deformation of the electric field distribution at the particle-oil interface. This increment can be seen clearly along the z-axis of the cross section plot of the electric field magnitude, as shown in Figure 10. The maximum electric field induces or polarizes the electric double layer of conductive particles and semiconductive particles in a very short timescale. 
This generates positive charges in the upper hemisphere and negative charges in the lower hemisphere, according to the electric field direction. As a result, free electrons initiated from the surroundings due to ionization or charge injection move quickly and are trapped in the positively-charged hemisphere until fully saturated [11]. $\mathrm{Fe}_{3} \mathrm{O}_{4}$ experiences a higher increment of the electric field magnitude. Hence, it highly induces positive charges and traps more free electrons than $\mathrm{TiO}_{2}$.

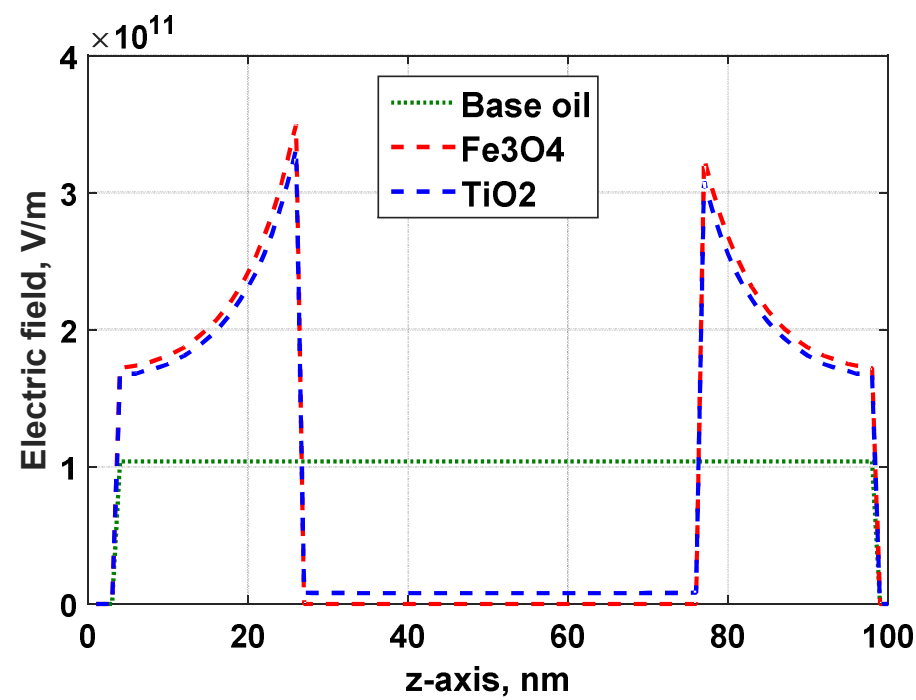

Figure 10. Cross section plot of the electric field magnitude from the FEA model in Figure 9.

In general, partial discharge (PD) happens once the electric field stress reaches a certain value, which is the inception field. To explain this mechanism in nanofluids, two conditions are considered: (1) inception and (2) steady-state.

PD inception voltage is usually recorded as the applied voltage at which the first PD occurs. It is also considered as a precursor to the incipient dielectric fault of insulation material [26]. This initiation process is random and strongly governed by the local electric field deployed within the electrode-material-electrode system. In the case of nanofluids, the presence of nanoparticles modifies the degree of heterogeneity of the electric field in the nanofluids, which depends on the nanoparticle properties and their dispersion in the base oil [27]. Local intensity of the electric field can result in localized PD occurrences at the same ionization level and applied voltage. As a result, the fluid interphases near the electrode ionize high-mobility electrons and low-mobility ions. Therefore, under the influence of electric field force, they are set up to migrate between two electrode polarities. At such conditions, the nanoparticles begin to act as electrons and negative ion scavengers, which generate a potential well, as depicted in Figure 11a [15].

At PD steady-state condition, assuming the nanoparticles are fully attached and charge-saturated, charges will drive the nanoparticles to move towards the opposite electrode at a very low speed. This is due to dielectrophoretic forces [28], which are responsible for the formation of particle clustering, as illustrated in Figure 11b. This mechanism accelerates the aggregation of nanoparticles along with PD activities, according to their respective concentration levels. For instance, the increase of $\mathrm{Fe}_{3} \mathrm{O}_{4}$ over a certain amount could cause higher PD activities, hypothetically due to the easy formation of conduction interphases. Within a high electric field, accumulated conductive interphase could be converted into a micro-bridging conductive channel [29] and are efficiently utilised by rapid streamer propagation, consequently leading to breakdown [30]. This is the main disadvantage of conductive nanoparticles compared to semiconductive or insulating nanoparticles especially in higher concentrations in base oil.

The results of tan delta and PD activities of natural ester-based nanofluid insulation under the presence of $\mathrm{Fe}_{3} \mathrm{O}_{4}$ and $\mathrm{TiO}_{2}$ are inter-connected. It is well known that tan delta can be used as an efficient tool to assess the insulation performance of the insulating materials [31]. The presence of nanoparticles in the base oil has a significant effect on the tan delta of natural ester. In the case of CNF, 
the nanofluid is sensitive to polarization and may enhance the tan delta. This can also explain why PD can occur easily in CNF compared to SNF. Higher tan delta and lower PD resistance of nanofluids are consistent with solid nanodielectrics, as reported by previous researchers [6], who describe the inter-relationship between the insulation property under low electric field (tan delta) and high electric field (partial discharge). More importantly, the tan delta and PD pattern for different nanoparticle types and concentrations are the findings that most need to be addressed. They could potentially influence the insulation performance when nanofluids are applied in a power apparatus in the future.

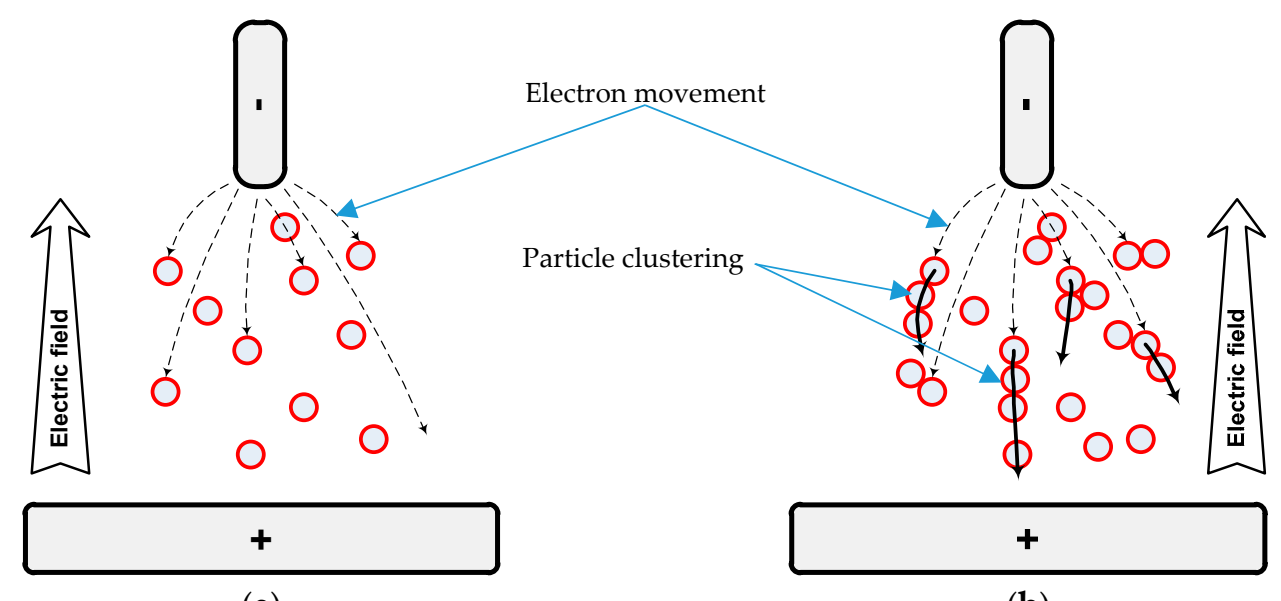

(a)

(b)

Figure 11. Schematic diagram of electron movement for nanofluids between two electrodes (a) at inception condition and (b) steady state condition.

\section{Conclusions}

Partial discharge (PD) activities in natural ester-based nanofluid have profound characteristics, according to nanoparticle types and concentrations. The results obtained in this work indicate that nanostructuration significantly improves the dielectric strength of insulating oil in low amounts of both nanoparticle types $(0.01 \mathrm{~g} / \mathrm{L})$. Consequently, the tan delta is decreased and PD resistance is enhanced with the appropriate amount of nanoparticles. However, a high concentration of conductive nanoparticles, such as $\mathrm{Fe}_{3} \mathrm{O}_{4}$, can increase tan delta value, promoting the PD activities and aggregation process simultaneously.

Since the influence of dielectrophoretic forces on natural ester with conductive nanoparticles (CNF) is more vigorous compared to natural ester with semiconductive nanoparticles (SNF), in terms of formation of interphase conduction as a result of PD activities, it is reasonable to suggest that SNF is more suitable to be applied as an insulation material in high voltage power equipment.

Author Contributions: M.Z.H.M., H.A.I., and C.Y.C. designed the study. M.Z.H.M. performed the experiment, analyzed the results, and wrote the paper with the feedback from H.A.I., C.Y.C., and S.Z.A.D.

Acknowledgments: The authors thank the University of Malaya and Ministry of Higher Education, Malaysia, for supporting this work through research grants of HIR (H-16001-D000048), Postgraduate Research Fund (PG236-2016A), Faculty Research Grant (GPF077A-2018), and scholarship under SLAB.

Conflicts of Interest: The authors declare no conflict of interest.

\section{References}

1. Contreras, J.E.; Rodriguez, E.A.; Taha-Tijerina, J. Nanotechnology applications for electrical transformers-A review. Electr. Power Syst. Res. 2017, 143, 573-584. [CrossRef]

2. Fal, J.; Mahian, O.; Żyła, G. Nanofluids in the Service of High Voltage Transformers: Breakdown Properties of Transformer Oils with Nanoparticles, a Review. Energies 2018, 11, 2942. [CrossRef]

3. Primo, V.A.; Garcia, B.; Albarracin, R. Improvement of transformer liquid insulation using nanodielectric fluids: A review. IEEE Electr. Insul. Mag. 2018, 34, 13-26. [CrossRef] 
4. Pompili, M.; Bartnikas, R. On partial discharge measurement in dielectric liquids. IEEE Trans. Dielectr. Electr. Insul. 2012, 19, 1476-1481. [CrossRef]

5. Herchl, F.; Marton, K.; Tomčo, L.; Kopčanský, P.; Timko, M.; Koneracká, M.; Kolcunová, I. Breakdown and partial discharges in magnetic liquids. J. Phys. Condens. Matter 2008, 20, 204110. [CrossRef] [PubMed]

6. Tanaka, T. Dielectric nanocomposites with insulating properties. Dielectr. Electr. Insul. IEEE Trans. 2005, 12, 914-928. [CrossRef]

7. Nelson, J.K. Dielectric Polymer Nanocomposites, 1st ed.; Springer US: New York, NY, USA, 2010; ISBN 978-1-4419-1591-7.

8. Zhong, X.; Wu, G.; Yang, Y.; Wu, X.; Lei, Y. Effects of nanoparticles on reducing partial discharge induced degradation of polyimide/Al2O3 nanocomposites. IEEE Trans. Dielectr. Electr. Insul. 2018, 25, 594-602. [CrossRef]

9. Jin, H.; Morshuis, P.; Mor, A.R.; Smit, J.J.; Andritsch, T. Partial discharge behavior of mineral oil based nanofluids. IEEE Trans. Dielectr. Electr. Insul. 2015, 22, 2747-2753. [CrossRef]

10. Tian, W.; Tang, C.; Wang, Q.; Zhang, S.; Yang, Y.; Tian, W.; Tang, C.; Wang, Q.; Zhang, S.; Yang, Y. The Effect and Associate Mechanism of Nano SiO2 Particles on the Diffusion Behavior of Water in Insulating Oil. Materials 2018, 11, 2373. [CrossRef] [PubMed]

11. Hwang, J.G.; Zahn, M.; O'Sullivan, F.M.; Pettersson, L.A.A.; Hjortstam, O.; Liu, R. Effects of nanoparticle charging on streamer development in transformer oil-based nanofluids. J. Appl. Phys. 2010, 107, 014310. [CrossRef]

12. Zhong, Y.; Lv, Y.; Li, C.; Du, Y.; Chen, M.; Zhang, S.; Zhou, Y.; Chen, L. Insulating properties and charge characteristics of natural ester fluid modified by $\mathrm{TiO} 2$ semiconductive nanoparticles. Dielectr. Electr. Insul. IEEE Trans. 2013, 20, 135-140. [CrossRef]

13. Sima, W.; Shi, J.; Yang, Q.; Huang, S.; Cao, X. Effects of conductivity and permittivity of nanoparticle on transformer oil insulation performance: Experiment and theory. Dielectr. Electr. Insul. IEEE Trans. 2015, 22, 380-390. [CrossRef]

14. Mohamad, N.; Azis, N.; Jasni, J.; Ab Kadir, M.; Yunus, R.; Yaakub, Z.; Mohamad, N.A.; Azis, N.; Jasni, J.; $\mathrm{Ab}$ Kadir, M.Z.A.; et al. Ageing Study of Palm Oil and Coconut Oil in the Presence of Insulation Paper for Transformers Application. Materials 2018, 11, 532. [CrossRef] [PubMed]

15. Makmud, M.; Illias, H.; Chee, C.; Sarjadi, M. Influence of Conductive and Semi-Conductive Nanoparticles on the Dielectric Response of Natural Ester-Based Nanofluid Insulation. Energies 2018, 11, 333. [CrossRef]

16. Lau, K.Y.; Vaughan, A.S.; Chen, G.; Hosier, I.L.; Holt, A.F. On the dielectric response of silica-based polyethylene nanocomposites. J. Phys. D. Appl. Phys. 2013, 46, 095303. [CrossRef]

17. Mansour, D.-E.A.; Elsaeed, A.M.; Izzularab, M.A. The role of interfacial zone in dielectric properties of transformer oil-based nanofluids. IEEE Trans. Dielectr. Electr. Insul. 2016, 23, 3364-3372. [CrossRef]

18. Liu, D.; Pourrahimi, A.M.; Pallon, L.K.H.; Sánchez, C.C.; Olsson, R.T.; Hedenqvist, M.S.; Fogelström, L.; Malmström, E.; Gedde, U.W. Interactions between a phenolic antioxidant, moisture, peroxide and crosslinking by-products with metal oxide nanoparticles in branched polyethylene. Polym. Degrad. Stab. 2016, 125, 21-32. [CrossRef]

19. Cavallini, A.; Karthik, R.; Negri, F. The effect of magnetite, graphene oxide and silicone oxide nanoparticles on dielectric withstand characteristics of mineral oil. IEEE Trans. Dielectr. Electr. Insul. 2015, 22, 2592-2600. [CrossRef]

20. Illias, H.; Chen, G.; Lewin, P. Partial discharge behavior within a spherical cavity in a solid dielectric material as a function of frequency and amplitude of the applied voltage. IEEE Trans. Dielectr. Electr. Insul. 2011, 18, 432-443. [CrossRef]

21. Du, Y.; Lv, Y.; Li, C.; Chen, M.; Zhong, Y.; Zhou, J.; Li, X.; Zhou, Y. Effect of semiconductive nanoparticles on insulating performances of transformer oil. IEEE Trans. Dielectr. Electr. Insul. 2012, 19, 770-776.

22. Rafiq, M.; Lv, Y.; Li, C. A Review on Properties, Opportunities, and Challenges of Transformer Oil-Based Nanofluids. J. Nanomater. 2016, 2016, 24. [CrossRef]

23. Ibrahim, M.E.; Abd-Elhady, A.M.; Izzularab, M.A. Effect of nanoparticles on transformer oil breakdown strength: Experiment and theory. IET Sci. Meas. Technol. 2016, 10, 839-845. [CrossRef]

24. Sima, W.; Shi, J.; Yang, Q.; Yu, F. Surface modification of nanoparticle and its charging dynamics during streamer discharge in transformer oil. Nanosci. Nanotechnol. Lett. 2014, 6, 424-430. [CrossRef] 
25. Velasco, J.; Frascella, R.; Albarracín, R.; Burgos, C.J.; Dong, M.; Ren, M.; Yang, L. Comparison of Positive Streamers in Liquid Dielectrics with and without Nanoparticles Simulated with Finite-Element Software. Energies 2018, 11, 361. [CrossRef]

26. Illias, H.A.; Tunio, M.A.; Mokhlis, H.; Chen, G.; Bakar, A.H.A. Experiment and modeling of void discharges within dielectric insulation material under impulse voltage. IEEE Trans. Dielectr. Electr. Insul. 2015, 22, 2252-2260. [CrossRef]

27. Lv, Y.; Ge, Y.; Wang, L.; Sun, Z.; Zhou, Y.; Huang, M.; Li, C.; Yuan, J.; Qi, B. Effects of Nanoparticle Materials on Prebreakdown and Breakdown Properties of Transformer Oil. Appl. Sci. 2018, 8, 601. [CrossRef]

28. Negri, F.; Cavallini, A. Effect of dielectrophoretic forces on nanoparticles. IEEE Trans. Dielectr. Electr. Insul. 2017, 24, 1708-1717. [CrossRef]

29. Zare, Y.; Rhee, K.Y. Development of a Model for Electrical Conductivity of Polymer/Graphene Nanocomposites Assuming Interphase and Tunneling Regions in Conductive Networks. Ind. Eng. Chem. Res. 2017, 56, 9107-9115. [CrossRef]

30. Peppas, G.D.; Bakandritsos, A.; Charalampakos, V.P.; Pyrgioti, E.C.; Tucek, J.; Zboril, R.; Gonos, I.F. Ultrastable Natural Ester-Based Nanofluids for High Voltage Insulation Applications. ACS Appl. Mater. Interfaces 2016, 8, 25202-25209. [CrossRef] [PubMed]

31. Dabbak, S.Z.; Illias, H.A.; Ang, B.C. Effect of surface discharges on different polymer dielectric materials under high field stress. IEEE Trans. Dielectr. Electr. Insul. 2017, 24, 3758-3765. [CrossRef]

(C) 2019 by the authors. Licensee MDPI, Basel, Switzerland. This article is an open access article distributed under the terms and conditions of the Creative Commons Attribution (CC BY) license (http://creativecommons.org/licenses/by/4.0/). 